Article

\title{
Biosynthesis of $N$-Docosahexanoylethanolamine from Unesterified Docosahexaenoic Acid and Docosahexaenoyl-Lysophosphatidylcholine in Neuronal Cells
}

\author{
Karl Kevala ${ }^{1}$, Michel Lagarde ${ }^{2}{ }^{-}$, Arthur A. Spector ${ }^{1}$ and Hee-Yong Kim ${ }^{1, *}$ \\ 1 Laboratory of Molecular Signaling, National Institute of Alcohol Abuse and Alcoholism, \\ National Institutes of Health, Bethesda, MD 20892, USA; Karl.Kevala@nih.gov (K.K.); \\ spectora@mail.nih.gov (A.A.S.) \\ 2 CarMeN Laboratory, INSA-Lyon, 69100 Villeurbanne, France; michel.lagarde@insa-lyon.fr \\ * Correspondence: hykim@nih.gov; Tel.: +1-301-402-8746
}

Received: 30 October 2020; Accepted: 19 November 2020; Published: 20 November 2020

\begin{abstract}
We investigated the synthesis of $N$-docosahexaenoylethanolamine (synaptamide) in neuronal cells from unesterified docosahexaenoic acid (DHA) or DHA-lysophosphatidylcholine (DHA-lysoPC), the two major lipid forms that deliver DHA to the brain, in order to understand the formation of this neurotrophic and neuroprotective metabolite of DHA in the brain. Both substrates were taken up in Neuro2A cells and metabolized to $N$-docosahexaenoylphosphatidylethanolamine (NDoPE) and synaptamide in a time- and concentration-dependent manner, but unesterified DHA was 1.5 to 2.4 times more effective than DHA-lysoPC at equimolar concentrations. The plasmalogen NDoPE (pNDoPE) amounted more than $80 \%$ of NDoPE produced from DHA or DHA-lysoPC, with 16-carbon-pNDoPE being the most abundant species. Inhibition of $\mathrm{N}$-acylphosphatidylethanolamine-phospholipase D (NAPE-PLD) by hexachlorophene or bithionol significantly decreased the synaptamide production, indicating that synaptamide synthesis is mediated at least in part via NDoPE hydrolysis. NDoPE formation occurred much more rapidly than synaptamide production, indicating a precursor-product relationship. Although NDoPE is an intermediate for synaptamide biosynthesis, only about $1 \%$ of newly synthesized NDoPE was converted to synaptamide, possibly suggesting additional biological function of NDoPE, particularly for $\mathrm{PNDoPE}$, which is the major form of NDoPE produced.
\end{abstract}

Keywords: synaptamide; docosahexaenoic acid; lysophosphatidylcholine; $\mathrm{N}$-docosahexaenoyl phosphatidylethanolamine; plasmalogens; $N$-docosahexaenoyl phosphatidylethanolamine plasmalogen; $N$-acyl phosphatidylethanolamine-phospholipase $\mathrm{D} ; \mathrm{N}$-acylethanolamines; hexachlorophene; bithionol

\section{Introduction}

$\mathrm{N}$-docosahexaenoylethanolamine (synaptamide) is an endocannabinoid-like metabolite of docosahexaenoic acid (DHA) that is synthesized in the brain [1]. Synaptamide promotes neurogenesis, neurite growth, and synaptogenesis [2,3]. It also attenuates the lipopolysaccharide-induced neuroinflammatory response [4]. These effects are mediated by a cAMP (cyclic adenosine monophosphate)/protein kinase A-dependent pathway that is activated by synaptamide binding to GPR110 (ADGRF1), a Gs $\alpha$ protein-coupled receptor expressed in neural stem cells and the developing brain [5]. This pathway modulates the expression of neurogenic, synaptogenic, and proinflammatory genes and may be a novel target for neurodevelopmental and neuroprotective control [1]. 
Synaptamide is a structural analog of $N$-arachidonoylethanolamine (anandamide), the potent endocannabinoid synthesized in the brain from arachidonic acid [6,7]. Although the initial studies demonstrated that anandamide is synthesized by direct condensation of arachidonic acid and ethanolamine [8-10], subsequent studies indicated that this is unlikely to occur under physiological conditions [11]. The predominant mechanism of anandamide production in the brain is now considered to be the $N$-acylation phosphodiesterase pathway [12-17]. This involves the addition of arachidonate to the ethanolamine moiety of phosphatidylethanolamine (PE), forming an $\mathrm{N}$-acylphosphatidylethanolamine (NAPE) intermediate, followed by hydrolysis of the $\mathrm{N}$-acylethanolamine (NAE) group to form anandamide. The NAPE that is formed is present as both diacyl and plasmalogen forms [18-21].

The NAPE analogue, $\mathrm{N}$-docosahexaenoylphosphatidylethanolamine (NDoPE), has been detected in bovine retina and rabbit cornea, suggesting that like anandamide, synaptamide is synthesized from this intermediate [22,23]. In this study, we have investigated synaptamide formation from DHA in neuronal (Neuro2A) cells to determine whether NDoPE is indeed an intermediate in synaptamide synthesis in the brain. Because DHA can be delivered to the brain either as the free fatty acid or as DHA-lysophosphatidylcholine (DHA-lysoPC) [24-27], the production of NDoPE and synaptamide was compared when Neuro2A cells were incubated with either unesterified DHA or DHA-lysoPC.

\section{Results}

\subsection{Time-Dependent NDoPE and Synaptamide Synthesis}

Comparative data for DHA incorporation into NDoPE and conversion to synaptamide by Neuro2A cultures during a $24 \mathrm{~h}$ incubation is shown in Figure 1. The cells were incubated with a mixture containing $2 \mu \mathrm{M}$ unesterified $\left[{ }^{13} \mathrm{C}\right] \mathrm{DHA}$ and $2 \mu \mathrm{M}$ DHA-lysoPC containing $87 \%$ sn-1-DHA-lysoPC, in the presence of the fatty acid amide hydrolase (FAAH) inhibitor URB597. A linear increase in $\left[{ }^{13} \mathrm{C}\right] \mathrm{DHA}$ incorporation into $\mathrm{N}$-docosahexaenoyl moiety of NDoPE occurred during the first $8 \mathrm{~h}$, but no further appreciable increase was observed thereafter. Although the time-dependent increase of NDoPE production from DHA-lysoPC continued over the entire $24 \mathrm{~h}$ incubation, unesterified $\left[{ }^{13} \mathrm{C}\right] \mathrm{DHA}$ produced 1.3 to 5.8 times more NDoPE than DHA-lysoPC (Figure 1A).

Mass spectrometric analysis of the NDoPE demonstrated that 75 to $90 \%$ of the total DHA incorporated from both substrates was present in plasmalogen-NDoPE (pNDoPE) (Figure 1B) in comparison with diacyl-NDoPE (Figure 1C). For example, at 8 h, 4.6 times more DHA derived from unesterified DHA was incorporated into pNDoPE than into NDoPE. Further analysis of the pNDoPE indicated that more DHA from both DHA substrates was incorporated into the 16:0-plasmalogen NDoPE species (p16:0-NDoPE) than either p18-NDoPE or p18:1-NDoPE at each time point (Figure 1D).

Synaptamide production was measured in the incubation medium $[2,3,28]$. The amount produced by the Neuro2A cells from unesterified $\left[{ }^{13} \mathrm{C}\right] \mathrm{DHA}$ increased linearly during the first $8 \mathrm{~h}$ of incubation and then more slowly between 8 and $24 \mathrm{~h}$, whereas synaptamide production from DHA-lysoPC steadily increased throughout the $24 \mathrm{~h}$ incubation (Figure 1E). Between 4 to $24 \mathrm{~h}, 1.7$ to 4.2 times more synaptamide was synthesized from unesterified $\left[{ }^{13} \mathrm{C}\right] \mathrm{DHA}$ than from DHA-lysoPC.

Only a minute fraction of the DHA incorporated into NDoPE was converted to synaptamide in Neuro 2A cells. After $4 \mathrm{~h}$, the medium contained $26 \mathrm{fmol}$ synaptamide produced from unesterified $\left[{ }^{13} \mathrm{C}\right] \mathrm{DHA}$ and $8 \mathrm{fmol}$ produced from DHA-lysoPC. Approximately $3400 \mathrm{fmol}$ of NDoPE was produced from unesterified $\left[{ }^{13} \mathrm{C}\right] \mathrm{DHA}$ and $600 \mathrm{fmol}$ from DHA-lysoPC, indicating that synaptamide production accounted for only $0.76-1.3 \%$ of the DHA incorporated into total NDoPE. A similar result was obtained after $8 \mathrm{~h}$; synaptamide production accounted for only $1.2-2.7 \%$ of the unesterified DHA incorporated into NDoPE and $0.80-0.91 \%$ of the DHA from DHA-lysoPC incorporated into NDoPE. Even after $24 \mathrm{~h}$ of incubation, synaptamide production accounted for only $1.4-3.3 \%$ and $0.80-2.0 \%$ of the DHA from unesterified DHA and DHA-lysoPC incorporated into NDoPE, respectively. 

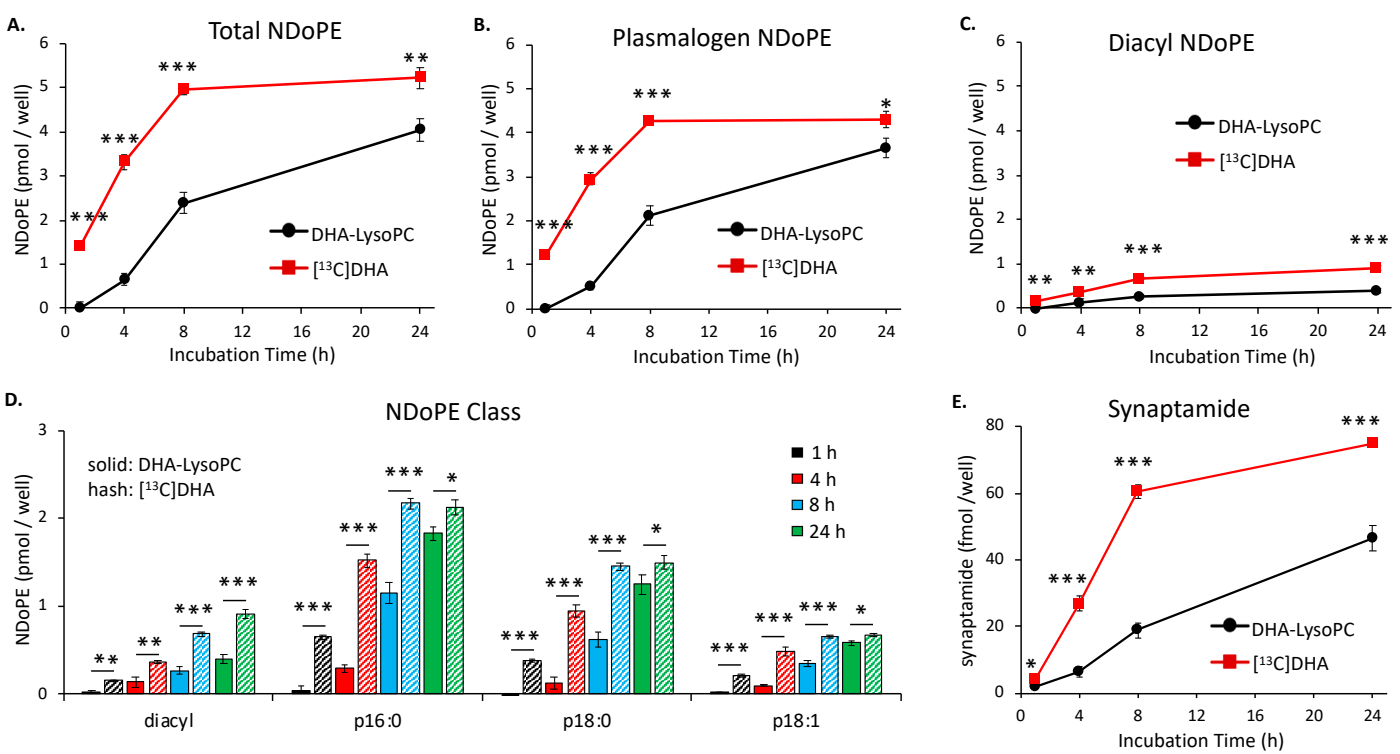

Figure 1. Time-dependent production of $N$-docosahexaenoylphosphatidylethanolamine (NDoPE) and synaptamide from docosahexaenoic acid (DHA) and DHA-lysophosphatidylcholine (DHA-lysoPC) in Neuro2A cells. The cells were incubated with a mixture containing $2 \mu \mathrm{M}$ each of DHA-lysoPC and $\left[{ }^{13} \mathrm{C}\right] \mathrm{DHA}$, and $2 \mu \mathrm{M}$ URB597 at $37{ }^{\circ} \mathrm{C}$, and the production of NDoPE (A-D) and synaptamide (E) from these substrates was comparatively evaluated using LC-MS/MS. The production of total NDoPE (A), plasmalogen NDoPE (B), and diacyl NDoPE (C) from DHA and DHA-lysoPC was determined from cell extract in the presence of diacyl or plasmalogen $\mathrm{N}$-17:1-phosphatidylethanolamine (PE) internal standards after methylamine-mediated deacylation. The main plasmalogen NDoPE species (p16:0-, p18:0-, and p18:1-NDoPE) are shown along with diacyl NDoPE (D). Synaptamide production from DHA and DHA-lysoPC was determined from the culture medium using d4-synaptamide as an internal standard (E). Production of unlabeled synaptamide from DHA-lysoPC was adjusted by background subtraction on the basis of the basal values obtained from the untreated control cultures. The significance of the differential production of these metabolites from DHA and DHA-lysoPC was evaluated by $t$-test. The values are the mean \pm SD of three separate cultures. ${ }^{*} p<0.05 ;{ }^{* *} p<0.01$; $* * * p<0.001$.

\subsection{Concentration-Dependent NDoPE and Synaptamide Synthesis}

Figure 2 shows the concentration dependence of DHA incorporation into total NDoPE, pNDoPE, diacyl NDoPE, and synaptamide. The Neuro2A cells were incubated separately with increasing amounts of $\left[{ }^{13} \mathrm{C}\right] \mathrm{DHA}$ or $\left[{ }^{13} \mathrm{C}\right] \mathrm{DHA}-\mathrm{yss} \mathrm{PC}$ for $8 \mathrm{~h}$ at $37{ }^{\circ} \mathrm{C}$. At each substrate concentration, substantially more DHA from unesterified $\left[{ }^{13} \mathrm{C}\right] \mathrm{DHA}$ than $\left[{ }^{13} \mathrm{C}\right] \mathrm{DHA}-\mathrm{lysoPC}$ was incorporated into total NDoPE (Figure 2A), pNDoPE (Figure 2B), and diacyl NDoPE (Figure 2C). At each substrate concentration, pNDoPE accounted for about $80 \%$ of the total NDoPE derived from unesterified $\left[{ }^{13} \mathrm{C}\right] \mathrm{DHA}$ or $\left[{ }^{13} \mathrm{C}\right] \mathrm{DHA}-\mathrm{lysoPC}$. Among pNDoPE species, more DHA from each substrate was incorporated into the p16:0-NDoPE than either p18:0-NDoPE or p18:1-NDoPE (Figure 2D). Increasing amounts of synaptamide were also produced as the concentration of unesterified $\left[{ }^{13} \mathrm{C}\right] \mathrm{DHA}$ or $\left[{ }^{13} \mathrm{C}\right] \mathrm{DHA}-\mathrm{lysoPC}$ was raised (Figure 2E), but from 1.5 to 2.4 times more synaptamide was produced from unesterified $\left[{ }^{13} \mathrm{C}\right]$ DHA. Consistent with the results in Figure 1, the amount of synaptamide produced was only $0.67-1.1 \%$ of the DHA incorporated into total NDoPE in the incubations with unesterified $\left[{ }^{13} \mathrm{C}\right] \mathrm{DHA}$, and $0.58-1.8 \%$ in the incubations with $\left[{ }^{13} \mathrm{C}\right]$ DHA-lysoPC. 

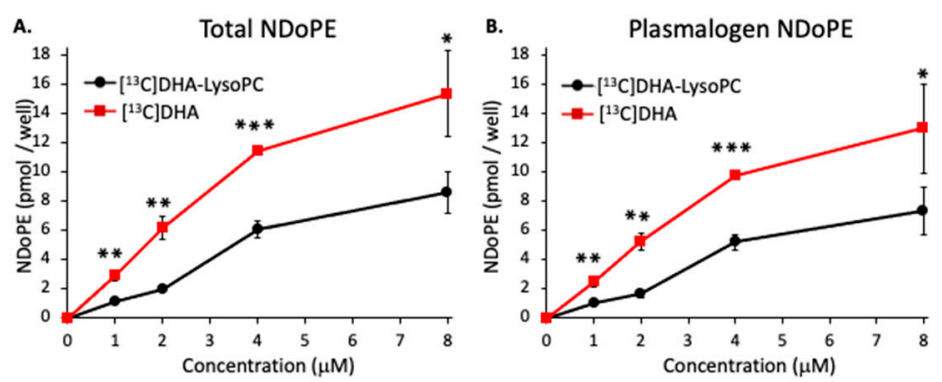

D.

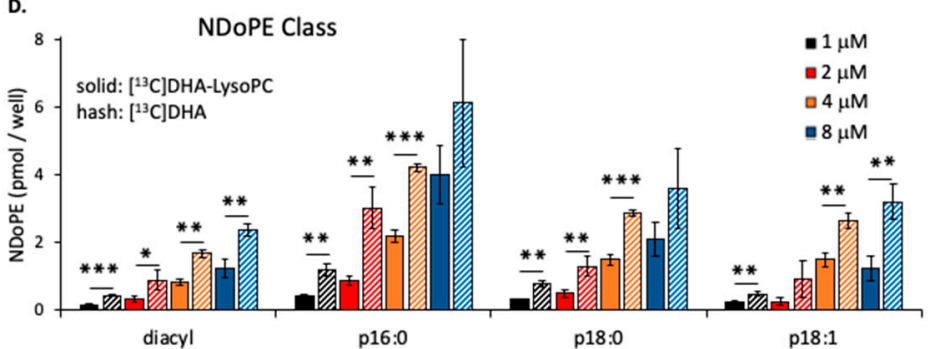

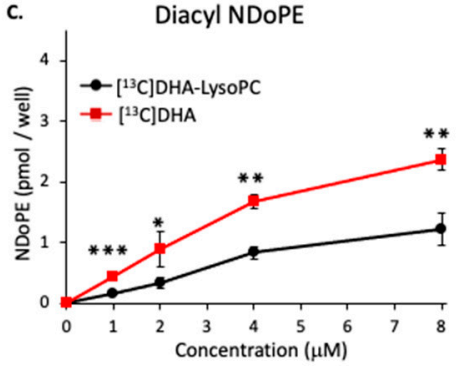

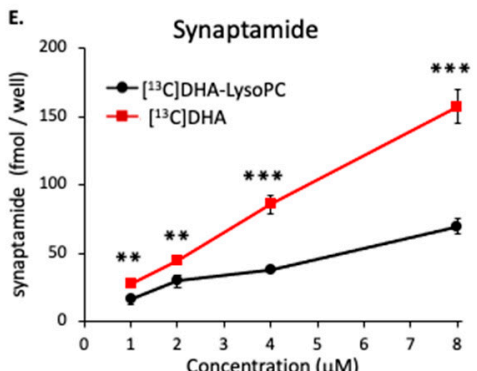

Figure 2. Concentration-dependent production of NDoPE and synaptamide from DHA and DHA-lysoPC. Neuro2A cells were incubated with either $\left[{ }^{13} \mathrm{C}\right] \mathrm{DHA}-\mathrm{lysoPC}$ or $\left[{ }^{13} \mathrm{C}\right] \mathrm{DHA}$ in the presence of $2 \mu \mathrm{M}$ URB597 for $8 \mathrm{~h}$ at $37{ }^{\circ} \mathrm{C}$. The production of total NDoPE (A), plasmalogen NDoPE (B), and diacyl NDoPE (C) from these two substrates were comparatively analyzed after methylamine-mediated deacylation of the cell lipid extract. The main plasmalogen NDoPE species (p16:0-, p18:0-, and p18:1-NDoPE) are shown along with diacyl NDoPE (D). The production of synaptamide extracted from culture media is shown in $(\mathrm{E})$. The significance of the differential production of these metabolites from DHA and DHA-lysoPC was evaluated by $t$-test. The values are the mean \pm SD of three separate cultures. ${ }^{*} p<0.05 ;{ }^{* *} p<0.01$; ${ }^{* * *} p<0.001$.

\subsection{Uptake of Unesterified DHA and DHA-lysoPC}

Figure 3 compares the total uptake of DHA in $8 \mathrm{~h}$ by Neuro2A cells incubated with increasing amounts of either unesterified DHA or DHA-lysoPC, as measured by gas-liquid chromatography (GC). Increasing amounts of DHA were taken up from both substrates over this range of concentrations. However, at 2, 4, and $8 \mu \mathrm{M}$, the DHA uptake from unesterified DHA was 55, 65, and 90\% greater than the amount taken up from DHA-lysoPC.

On the basis of these comparative uptake results, we recalculated production of NDoPEs and synaptamide from unesterified DHA and DHA-lysoPC to account for the differential cellular incorporation of DHA from these precursors. Figure 4 shows that the production of total NDoPE (Figure 4A), pNDoPE (Figure 4B), diacyl NDoPE (Figure 4C), NDoPE molecular species (Figure 4D), and synaptamide (Figure 4E) from unesterified DHA and DHA-lysoPC was similar when normalized to account for the differences in DHA uptake. Statistical analysis after normalization indicated that only NDoPE production at 1 and $2 \mu \mathrm{M}$ showed significant differences between these two substrates, while no significance was found for synaptamide production. Normalization did not alter the higher production of pNDoPE in comparison diacyl-NDoPE, and p16:0-NDoPE still remained the most abundant NDoPE species. 


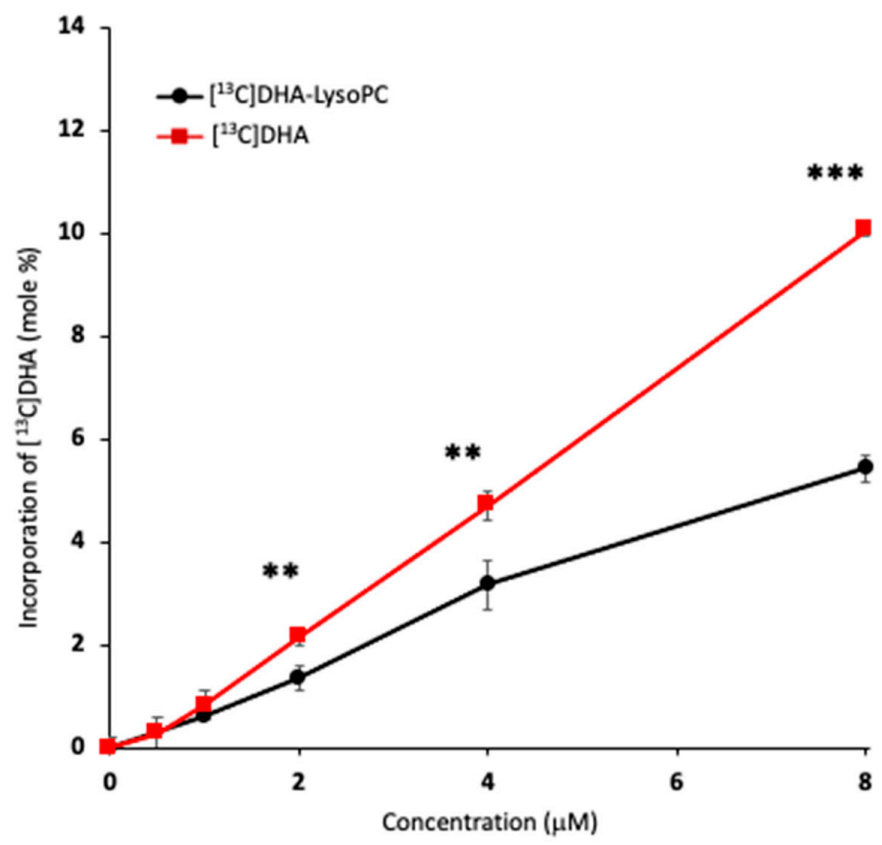

Figure 3. Concentration-dependent DHA incorporation into Neuro2A cells incubated with unesterified DHA or DHA-lysoPC. The cells were incubated with 1-8 $\mu \mathrm{M}\left[{ }^{13} \mathrm{C}\right] \mathrm{DHA}-1 y$ soPC or $\left[{ }^{13} \mathrm{C}\right] \mathrm{DHA}$ for $8 \mathrm{~h}$ at $37^{\circ} \mathrm{C}$ and the cellular DHA content was analyzed by gas-liquid chromatography (GC) after transmethylation using 23:0 free fatty acid as an internal standard. The total uptake of $\left[{ }^{13} \mathrm{C}\right]-\mathrm{DHA}$ by Neuro2A cells after the incubation with unesterified DHA or DHA-lysoPC was compared at equivalent concentrations after subtraction of basal DHA content. Values are the mean \pm SD of three separate cultures. ${ }^{* *} p<0.01 ;{ }^{* *} p<0.001$.
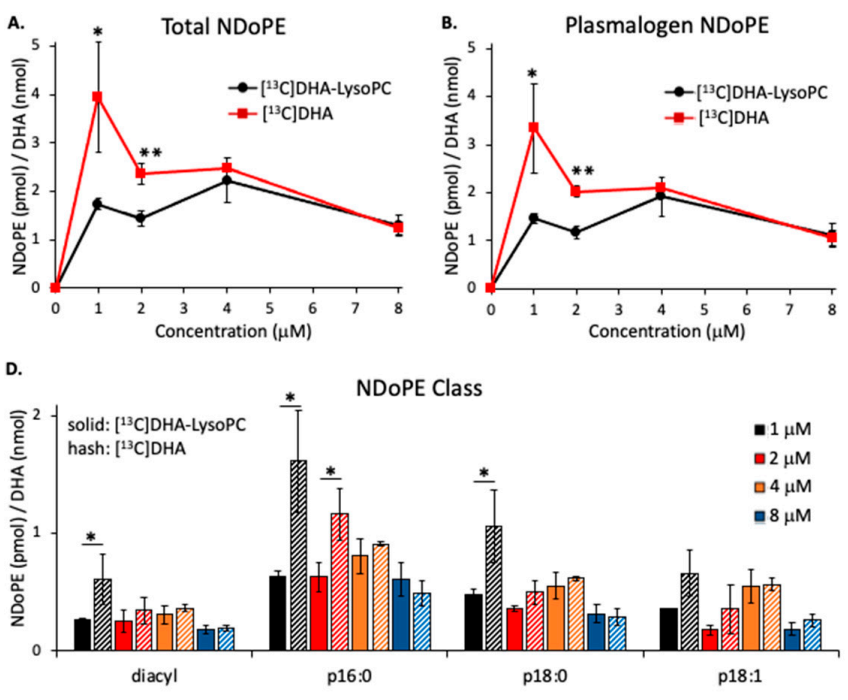
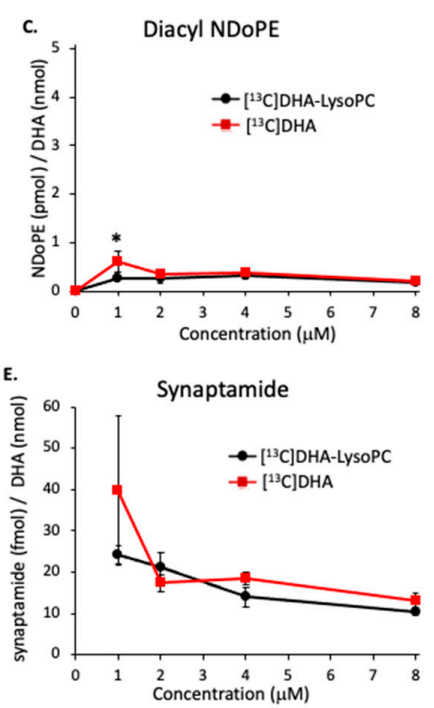

Figure 4. Comparative production profile of total NDoPE (A), pNDoPE (B), diacyl NDoPE (C), NDoPE molecular species (D), and synaptamide (E) from either $\left[{ }^{13} \mathrm{C}\right]$-labeled DHA or DHA-lysoPC after normalization for cellular DHA incorporation based on the data shown in Figure $3 * p<0.05$; ** $p<0.01$.

\subsection{Effect of NAPE-PLD Inhibition on Synaptamide Production}

The cytotoxicity of $N$-acylphosphatidylethanolamine-phospholipase D (NAPE-PLD) inhibition was assessed in Neuro2A cultures. Previous studies indicated that hexachlorophene and bithionol produced only small decreases in HEK293 cell viability at concentrations of 8 and $10.5 \mu \mathrm{M}$, 
respectively [29]. On the basis of this information, we tested the effect of these inhibitors on Neuro2A cells at a concentration of $10 \mu \mathrm{M}$. As shown in Figure 5, no cytotoxicity was observed in $1.5 \mathrm{~h}$ incubations, but a $10-20 \%$ reduction in cell viability occurred at $2.5 \mathrm{~h}$. Therefore, a $2 \mathrm{~h}$ incubation time, sufficient to obtain reproducible amounts of synaptamide production (Figure 1), was utilized to test the effect of the inhibitors on synaptamide production.

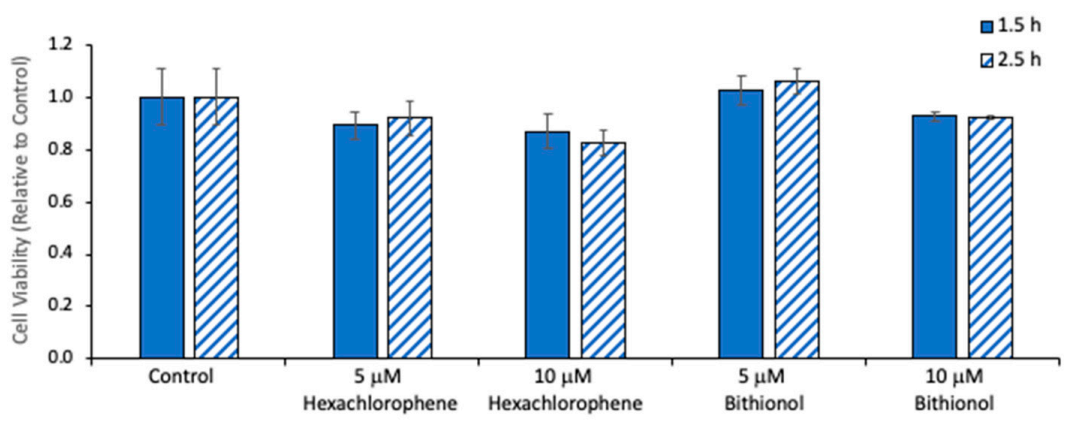

Figure 5. Effect of N-acylphosphatidylethanolamine-phospholipase D (NAPE-PLD) inhibitors on cell viability. Viability of Neuro2A cells was determined by ATP assay after incubation with hexachlorophene or bithionol at 5 or $10 \mu \mathrm{M}$ for 1.5 (solid) or $2.5 \mathrm{~h}$ (hash). The values are the mean $\pm \mathrm{SD}$ of three separate cultures.

As seen in Figure 6, $10 \mu \mathrm{M}$ hexachlorophene inhibited the production of $\left[{ }^{13} \mathrm{C}\right]$ synaptamide by $65 \%$ in Neuro2A cultures incubated with either 2 or $4 \mu \mathrm{M}\left[{ }^{13} \mathrm{C}\right] \mathrm{DHA}$ in the presence of URB597 (Figure 6A, middle set of bars). Bithionol inhibited $\left[{ }^{13} \mathrm{C}\right]$ synaptamide production to a similar extent (Figure $6 \mathrm{~B}$, middle set of bars). The production of synaptamide (left set of bars) and anandamide (right set of bars) derived from endogenous substrates was also reduced by these NAPE-PLD inhibitors.

A.

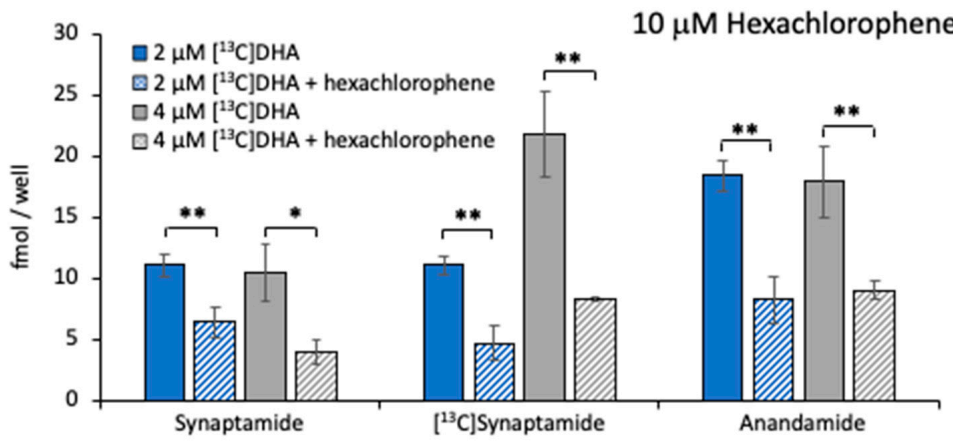

B.

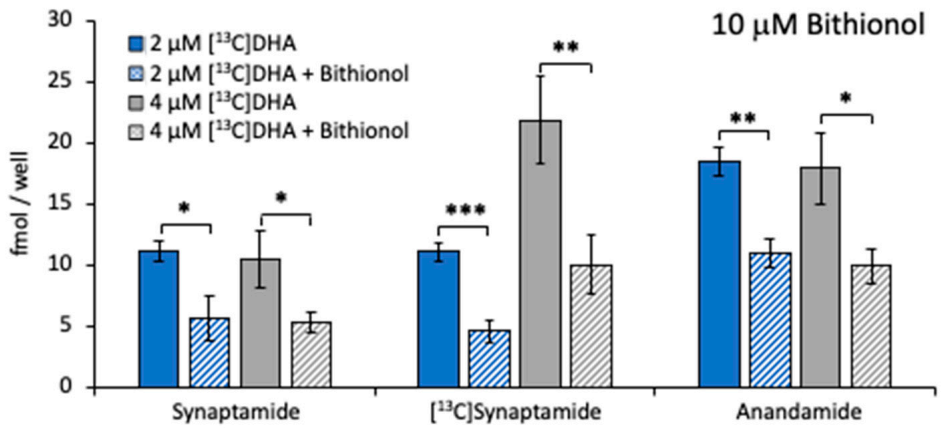

Figure 6. Effect of NAPE-PLD inhibition on synaptamide production. The Neuro2A cells were incubated with $10 \mu \mathrm{M}$ hexachlorophene (A) or $10 \mu \mathrm{M}$ bithionol (B) in the presence of $2 \mu \mathrm{M}$ URB597 for $2 \mathrm{~h}$ with either 2 or $4 \mu \mathrm{M}\left[{ }^{13} \mathrm{C}\right] \mathrm{DHA}$. The production of $\left[{ }^{13} \mathrm{C}\right]$ synaptmide as well as synaptamide and anandamide from endogenous sources was measured by LC-MS analysis. The values are the mean \pm SD of three separate cultures. ${ }^{*} p<0.05 ;{ }^{* *} p<0.01 ; * * * * 0.001$. 


\section{Discussion}

These findings demonstrate that DHA from either unesterified DHA or DHA-lysoPC can be incorporated into NDoPE and converted to synaptamide by neuronal cells. The incorporation of DHA into NDoPE occurred rapidly prior to the formation of synaptamide, as expected for a precursor-product relationship, and indicates that the rate of PE acylation by DHA to form NDoPE is much higher than the rate of NAPE-PLD hydrolysis to release synaptamide. The amount of synaptamide produced was substantially reduced when NAPE-PLD was inhibited by either hexachlorophene or bithionol. Taken together, these results indicate that synaptamide, like its $\omega-6$ structural analogue anandamide that is synthesized from arachidonic acid [13-17], can be produced in neuronal cells at least in part by NAPE-PLD-mediated hydrolysis of a NAPE intermediate.

Although the brain can take up DHA either in the form unesterified fatty acid or DHA-lysoPC [24-27], recent evidence suggests that the major source is sn-1-DHA-lysoPC [26]. However, the present results demonstrate that neuronal cells take up DHA by 1.5 to 2.4 times more from unesterified DHA than DHA-lysoPC when incubated with equimolar concentrations of these substrates. Greater uptake from unesterified DHA occurred when the substrates were incubated either together (Figure 1) or separately (Figure 2) with the cells, and 87\% of the DHA-lysoPC incubated with the cells was in the form of $s n-1-\mathrm{DHA}-1 y s o P C$, the isomer that is reported to be transported into the brain by the Mfsd2a transporter [26]. The findings that unesterified DHA is the more effective substrate for Neuro2A cells suggest that any selectivity for transport of DHA-lysoPC probably occurs at the level of the blood-brain barrier, not neuronal cells. Although more DHA from unesterified DHA than DHA-lysoPC was incorporated into NDoPE and synaptamide by the Neuro2A cells, the amounts were similar when they were normalized for the differences in uptake of these substrates (Figures 3 and 4). This suggests that the increased effectiveness of unesterified DHA for NDoPE and synaptamide production is due to the greater capacity of the neuronal cells to take up DHA. Nevertheless, DHA-lysoPC may still substantially contribute to the brain synaptamide production in vivo, as DHA-lysoPC can cross the blood-brain barrier around 10 times more efficiently than unesterified DHA [24].

The plasma concentration of unesterified DHA and DHA-lysoPC in rats was reported to be 1.1-7.7 [25,30] and $1.35 \mathrm{nmol} / \mathrm{mL}$ [30], respectively, indicating that both DHA forms are present in the similar micromolar range. The consensus estimates of unesterified DHA and DHA-lysoPC in human plasma are 1.5 and $0.75 \mathrm{nmol} / \mathrm{mL}$ [31], respectively, also in the low micromolar range. It was shown that DHA-lysoPC is more effective in targeting the brain for long-term accumulation, but unesterified DHA is kinetically faster in entering the brain [27]. While Mfsd2a is the reported transporter for DHA-lysoPC, it is uncertain whether DHA or other plasma unesterified fatty acids require a membrane transporter to be taken up by the brain. There is evidence indicating that uptake occurs by a diffusion mechanism that does not rely on a membrane protein transporter [32-34]. Other findings indicate that a membrane transporter and cytosolic fatty acid-binding protein are required for fatty acid uptake $[35,36]$. An integrated mechanism that involves diffusion across the lipid bilayer combined with targeting and desorption by binding proteins has been proposed recently [37]. However, further studies will be necessary to resolve this uncertainty regarding the mechanism of plasma unesterified DHA uptake by the brain.

The Neuro2A cells incorporated four times more DHA from either unesterified DHA or DHA-lysoPC into $N$-acyl moiety of pNDoPE than diacyl-NDoPE. This suggests that pNDoPE may be an important source of synaptamide synthesis in neuronal cells and possibly also in the brain. NAPE plasmalogens were detected initially in canine infarcted myocardium [38], and subsequent studies demonstrated their synthesis in homogenates of canine heart [19], canine brain [39], and rat brain [20]. NAPE plasmalogens also are present in fish brain and spinal cord [40], and they are synthesized by rat and dog brain homogenates [20,39]. The $N$-acyl moiety of the fish brain NAPE plasmalogens contains $0.8 \%$ DHA [40], and molecular species containing $N$-docosahexaenoyl moiety are present in the NAPE plasmalogens synthesized by COS-7 cells [21]. These results are consistent 
with the major presence of pNDoPE observed in this study, where exogenous sources of DHA are provided to Neuro 2A cells. In addition to the probable role as an intermediate for synaptamide synthesis, pNDoPE may have additional functions in neuronal cells as only less than $2 \%$ of pNDoPE is converted to synaptamide.

The finding that synaptamide production is decreased by NAPE-PLD inhibitors is consistent with the report that $N$-acylethanolamine production is inhibited in the brain of NAPE-PLD gene-deleted mice [41]. Due to cytotoxicity considerations (Figure 5), the concentrations of hexachlorophene or bithionol was limited to $10 \mu \mathrm{M}$ in the Neuro2A cell incubations. This probably accounts for the fact that the observed reductions in synaptamide production were only $50-60 \%$. However, there are other mechanisms for the production of NAE from NAPE, such as conversion of NAPE to lyso-NAPE or $\mathrm{N}$-acyl glycerylphosphorylethanolamine (GPE) prior to the phosphodiesterase-mediated hydrolysis of the NAE moiety [42,43]. In addition, NAE can be produced from NAPE by a phospholipase C-mediated pathway followed by dephosphorylation [44]. Accordingly, it is possible that one or more of these processes may mediate the conversion of the NDoPE to synaptamide, accounting for the incomplete inhibition obtained with the NAPE-PLD inhibitors.

Neuro2A cells also produced unlabeled synaptamide and anandamide during these incubations (Figure 6), indicating that neuronal cells can utilize inherent endogenous substrate stores in addition to the exogenously added $\left[{ }^{13} \mathrm{C}\right] \mathrm{DHA}$. The NAPE-PLD inhibitors significantly decreased the production of these endogenously derived NAEs, suggesting that they also may be formed via a NAPE intermediate. The considerable amount of synaptamide produced from exogenous DHA suggests that inherent synaptamide production in the brain may be increased by factors that stimulate DHA mobilization from neural lipid stores.

In summary, our findings demonstrate that synaptamide production is at least in part mediated through the hydrolysis of NDoPE by NAPE-PLD. Both NDoPE and synaptamide are synthesized in neuronal cells from unesterified DHA and 1-DHA-lyso-PC, two major forms for DHA delivery into the brain. Unesterified DHA is significantly more effective than 1-DHA-lyso-PC in the production of both NDoPE and synaptamide, although the difference is largely due to differences in incorporation efficiency of DHA from these substrates in neuronal cells. Accordingly, any factors that mobilize DHA from neural lipid stores may effectively raise the endogenous synaptamide level in the brain. While the plasmalogen species is the predominant form of NDoPE produced from both substrates, only a minute proportion of NDoPE is converted to synaptamide, suggesting additional function of NDoPE, particularly pNDoPE, other than the intermediary role in synaptamide synthesis.

\section{Materials and Methods}

\subsection{Substrate Lipids and Internal Standards}

Uniformly $\left[{ }^{13} \mathrm{C}\right]$-labeled DHA $\left(\left[{ }^{13} \mathrm{C}\right] \mathrm{DHA}\right)$ was a gift from Dr. Anthony Windust (National Research Council, Ottawa, Ontario, Canada), and we synthesized unlabeled and uniformly $\left[{ }^{13} \mathrm{C}\right]$-labeled DHA-lysoPC. Unlabeled DHA-lysoPC was made by lipolysis of 1-palmitoyl,2-docosahexaenoyl-glycerophosphorylcholine (16:0,22:6-PC) from Avanti Polar Lipids (Alabaster, AL, USA). Briefly, 16:0,22:6-PC in ethylacetate-water (50:50) was incubated with the immobilized lipozyme (Novo Nordisk, Bagsvaerd, Denmark) in the dark at room temperature under nitrogen for $24 \mathrm{~h}$. After centrifugation of the immobilized enzyme, and supernatant concentration, DHA-lysoPC was separated from the remaining 16:0,22:6-PC by thin-layer chromatography with chloroform-methanol-water 60:30:4 as eluant. DHA-lysoPC was quantified on the basis of DHA-methylester obtained by transmethylation, measured by capillary GC. $\left[{ }^{13} \mathrm{C}\right]$-labeled DHA-lysoPC was obtained by acylation of glycerophosphorylcholine (GPC) according to a method described to prepare 1-acetyl,2-DHA-GPC [45] without the acetylation step. GPC was dissolved in dimethylformamide, and added to 1,3- dicyclohexylcarbodiimide, 4-dimethylamino-pyridine, and $\left[{ }^{13} \mathrm{C}\right] \mathrm{DHA}$ for incubation in the dark at room temperature under nitrogen for $24 \mathrm{~h}$. The resulting 
$\left[{ }^{13} \mathrm{C}\right] \mathrm{DHA}-\mathrm{lys}$ oPC was purified by thin-layer chromatography and measured according to its DHA content by GC, as stated above for unlabeled DHA-lysoPC.

Diacyl and plasmalogen N-17:1 (number of carbons/number of double bonds)-NAPE were synthesized and purified as internal standards for NDoPE on the basis of procedures described in the literature [46]. Briefly, for diacyl species, $18.8 \mu \mathrm{L}$ (13.3 mM) 15:0,d7-18:1-PE (Avanti Polar Lipids, Alabaster, AL) in dichloromethane (DCM; Sigma-Aldrich, St. Louis, MO, USA) was added to $1.5 \mathrm{~mL}$ DCM. A total of $25 \mu \mathrm{L}$ of pyridine (Sigma-Aldrich) diluted in DCM (1:25 ratio) was added, followed by

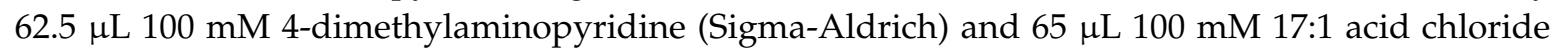
(NuChek Prep, Elysian, MN, USA), both in DCM. The mixture was vortexed and incubated overnight at room temperature. The reaction was quenched with saturated $\mathrm{NH}_{4} \mathrm{CO}_{3}$ (Sigma-Aldrich) and centrifuged for $3 \mathrm{~min}$ at $2500 \mathrm{rpm}$ (1294 RCF), and the upper phase was discarded. The organic layer was further washed with water several times, dried under $\mathrm{N}_{2}$, suspended in $1 \mathrm{~mL}$ methyl-t-butyl ether (MTBE; Sigma-Aldrich)/chloroform $\left(\mathrm{CHCl}_{3}\right.$; Thermo Fisher Scientific, Pittsburgh, PA, USA)/acetic acid (Thermo Fisher Scientific) (98:2:0.2), and subjected to solid phase extraction (SPE) (Extract-Clean silica, $1000 \mathrm{mg} / 1.5 \mathrm{~mL}$, American Chromatography Supplies, Vineland, NJ, USA), similar to the method described in [47]. N-17:1-PE was eluted into $\mathrm{MTBE} / \mathrm{CHCl}_{3} /$ methanol (Thermo Fisher Scientific) (50:20:30). The eluant was dried under argon and stored at $-80{ }^{\circ} \mathrm{C}$ in $2: 1 \mathrm{CHCl}_{3} /$ methanol containing $50 \mathrm{mg} / \mathrm{L} t$-butyl hydroxytoluene (BHT, Sigma-Aldrich). For the synthesis of plasmalogen N-17:1-PE, p18:0,20:4-PE (Avanti Polar Lipids) was utilized as substrate.

Deuterated synaptamide internal standard (d4-synaptamide) was synthesized by dropwise addition of $100 \mu \mathrm{L}$ deuterated ethanolamine (d4-ethanolamine, Cambridge Isotope Laboratories, Tewksbury, MA, USA) into ice-cold DCM solution containing $100 \mathrm{mg}$ docosahexaenoyl chloride (NuChek Prep). The mixture was incubated for $15 \mathrm{~min}$ on ice and washed several times with liquid chromatography/mass spectrometry (LC-MS)-grade water (Thermo Fisher Scientific) until the final 2 washes were $\mathrm{pH}$-neutral. The organic layer was dried under $\mathrm{N}_{2}$, suspended in methanol, and stored under argon at $-80^{\circ} \mathrm{C}$.

The quantity of lipid substrates, N-17:1-PE, and d4-synaptamide internal standards was calibrated by GC after transmethylation. The positional (1- versus 2-DHA-lysoPC) as well as ${ }^{13} \mathrm{C}$ isotopic distribution of DHA-lysoPC and unesterified DHA was characterized by LC-high-resolution MS in both positive and negative mode, using LC conditions described for the synaptamide analysis (Figure 7). Approximately $87 \%$ of DHA-lysoPC was 1-DHA-lysoPC (Figure 7A), and $68 \%$ of $\left[{ }^{13} \mathrm{C}\right] \mathrm{DHA}$ was the fully labeled isotope, $\left[{ }^{13} \mathrm{C}_{22}\right] \mathrm{DHA}$ (Figure 7B).

\subsection{Cell Culture and Incubation with Lipid Substrates}

Mouse neuroblastoma Neuro2A cells (ATCC, Manassas, VA, USA) were grown in glutamine-free, low glucose Dulbecco's minimum essential medium (DMEM; Sigma-Aldrich) containing 5\% fetal bovine serum (FBS; Sigma-Aldrich) and penicillin/streptomycin antibiotic (Gibco, Gaithersburg, MD, USA) at $37^{\circ} \mathrm{C}$ in a $5 \% \mathrm{CO}_{2}$ atmosphere for up to 4 passages. Prior to treatment with lipid substrate(s), approximately $2.5 \times 10^{4}$ cells $/ \mathrm{cm}^{2}$ were seeded into 6-well plates or $10 \mathrm{~cm}$ cell culture dishes, and after $24 \mathrm{~h}$, the cultures were transferred to $0.25 \%$ FBS media. A FAAH inhibitor URB597 (Sigma-Aldrich) was included to prevent synaptamide hydrolysis $[2,3,28]$.

The lipid substrate for the time-dependent studies was a mixture of unlabeled DHA-lysoPC and $\left[{ }^{13} \mathrm{C}\right] \mathrm{DHA}$, while the concentration-dependent studies used each $\left[{ }^{13} \mathrm{C}\right]$-labeled substrate separately. Dimethyl sulfoxide (DMSO; Sigma-Aldrich) stocks of the URB597 fatty acid amide hydrolase (FAAH) inhibitor and vitamin E (Sigma-Aldrich) containing appropriate lipid substrates were prepared. At $24 \mathrm{~h}$ after transfer to the $0.25 \%$ FBS medium, DMSO mixture was added to $0.25 \%$ FBS in DMEM, such that final media contained 0.1\% DMSO, $2 \mu \mathrm{M}$ URB597, $40 \mu \mathrm{M}$ vitamin $\mathrm{E}$, and $2 \mu \mathrm{M}$ of each lipid substrate for time-dependence studies. For the concentration-dependence studies, each labeled substrate at 1-8 $\mu \mathrm{M}$ was incubated for $8 \mathrm{~h}$. At the end of incubation, the media was collected and BHT-methanol was added to make a $30 \%$ aqueous solution. Cells were washed twice with phosphate-buffered saline 
(PBS; Gibco). Both media and cells plates, with $0.8 \mathrm{~mL}$ PBS added per well, were stored at $-80^{\circ} \mathrm{C}$ until processing.
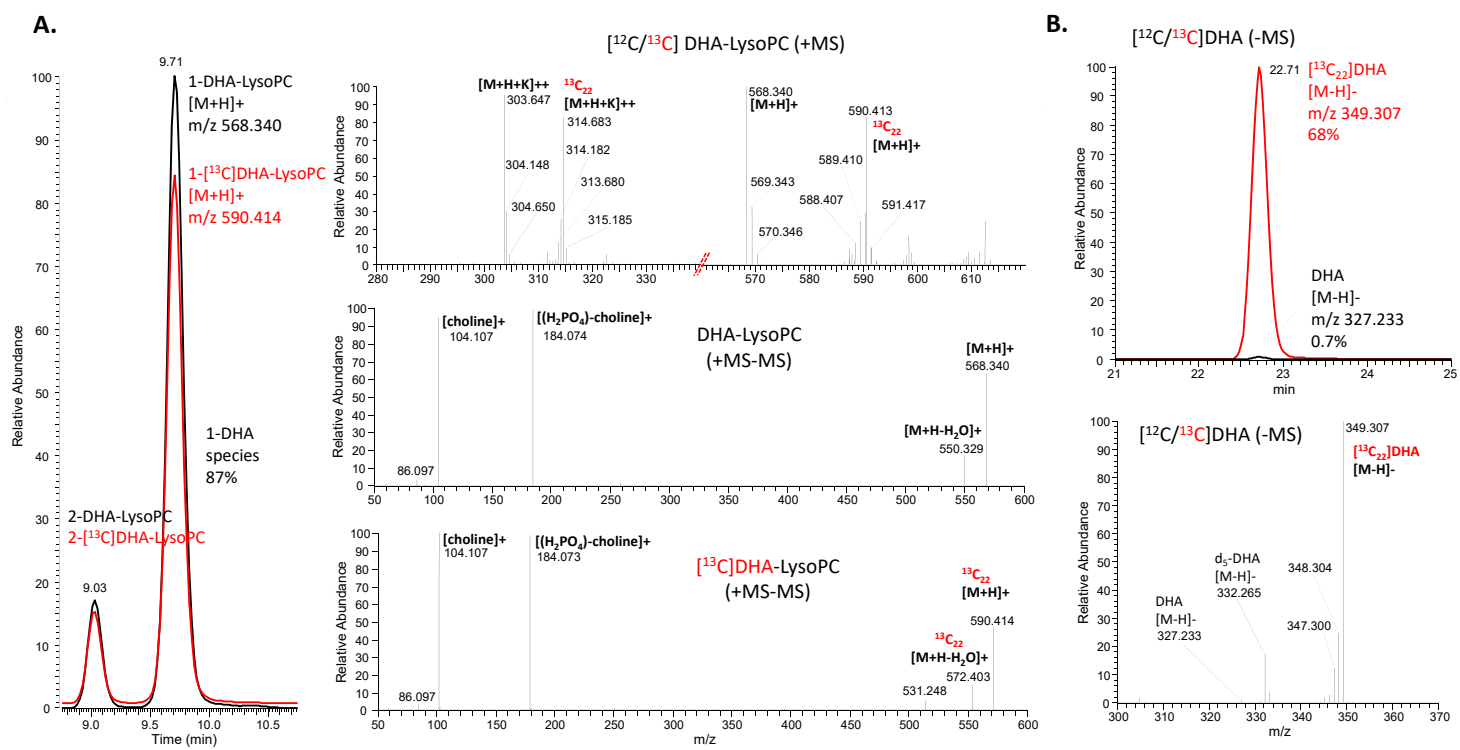

Figure 7. Characterization of $\left[{ }^{13} \mathrm{C}\right] \mathrm{DHA}-\mathrm{lys}$ soPC and $\left[{ }^{13} \mathrm{C}\right] \mathrm{DHA}$ used as substrates. The DHA-lysoPC was analyzed by LC-MS and LC-MS/MS in the positive ion mode (A), and $\left[{ }^{13} \mathrm{C}\right] \mathrm{DHA}$ by LC-MS in the negative ion mode (B). Approximately $87 \%$ of labeled or unlabeled DHA-lysoPC was sn-1-DHA isomer. Approximately $30 \%$ of DHA-lysoPC was fully labeled with $\left[{ }^{13} \mathrm{C}_{22}\right]$ (A), while approximately $68 \%$ of unesterified $\left[{ }^{13} \mathrm{C}\right]$ DHA was fully labeled $\left[{ }^{13} \mathrm{C}_{22}\right]$ DHA (B). Unlabeled free DHA was present at only $0.7 \%$. The positional and/or isotopic distribution of the substrates was accounted for the quantitative evaluation of labeled products, NDoPEs and synaptamide. A pair of red dotted lines in the X-axis of

(A) indicates a break in the $\mathrm{m} / \mathrm{z}$ scale.

\subsection{Deacylated NDoPE Analysis}

Cells were scraped into glass tubes and suspended in PBS/BHT-methanol/chloroform (0.8:2:1) with internal standards including a diacyl and plasmalogen N-17:1-NAPE (15:0,d7-18:1 and p18:0,20:4 species), deuterated phospholipid species (d35-18:0,18:1-PE, p18:0,d9-18:1-PE, d35-18:0-lysoPC (Avanti Polar Lipids)), and 23:0 (Nu-Chek Prep). Lipids were extracted according to the method of Bligh and Dyer [48]. Depletion of phospholipids from $90 \%$ of the Bligh-Dyer extracts was achieved by silica SPE using the same solvent system described for $N$-acyl 17:1 NAPE synthesis [38]. The SPE eluant was dried and chemically deacylated in $240 \mu \mathrm{L}$ of methylamine ( $40 \%$ aqueous, Sigma-Aldrich)/BHT-methanol/1-butanol (Sigma-Aldrich) (4:4:1) mixture at $53{ }^{\circ} \mathrm{C}$ [39] for $90 \mathrm{~min}$. The product was dried under $\mathrm{N}_{2}$, resuspended in $1 \mathrm{~mL}$ of BHT-methanol/water containing $0.1 \%$ acetic acid (Thermo Fisher Scientific) (7:3), and loaded onto strata-X polymeric reverse-phase SPE cartridges (Phenomenex, Torrance, CA, USA) pre-equilibrated with water. After washing with $1 \mathrm{~mL}$ of the loading solvent followed by $3 \mathrm{~mL}$ water (neutral), deacylated NDoPE species were eluted with $3 \mathrm{~mL}$ of BHT-methanol, dried under $\mathrm{N}_{2}$, and suspended in approximately $17 \mu \mathrm{L}$ of BHT-methanol for LC-MS/MS analysis (Figure 8A). 
A. NDoPE Analysis

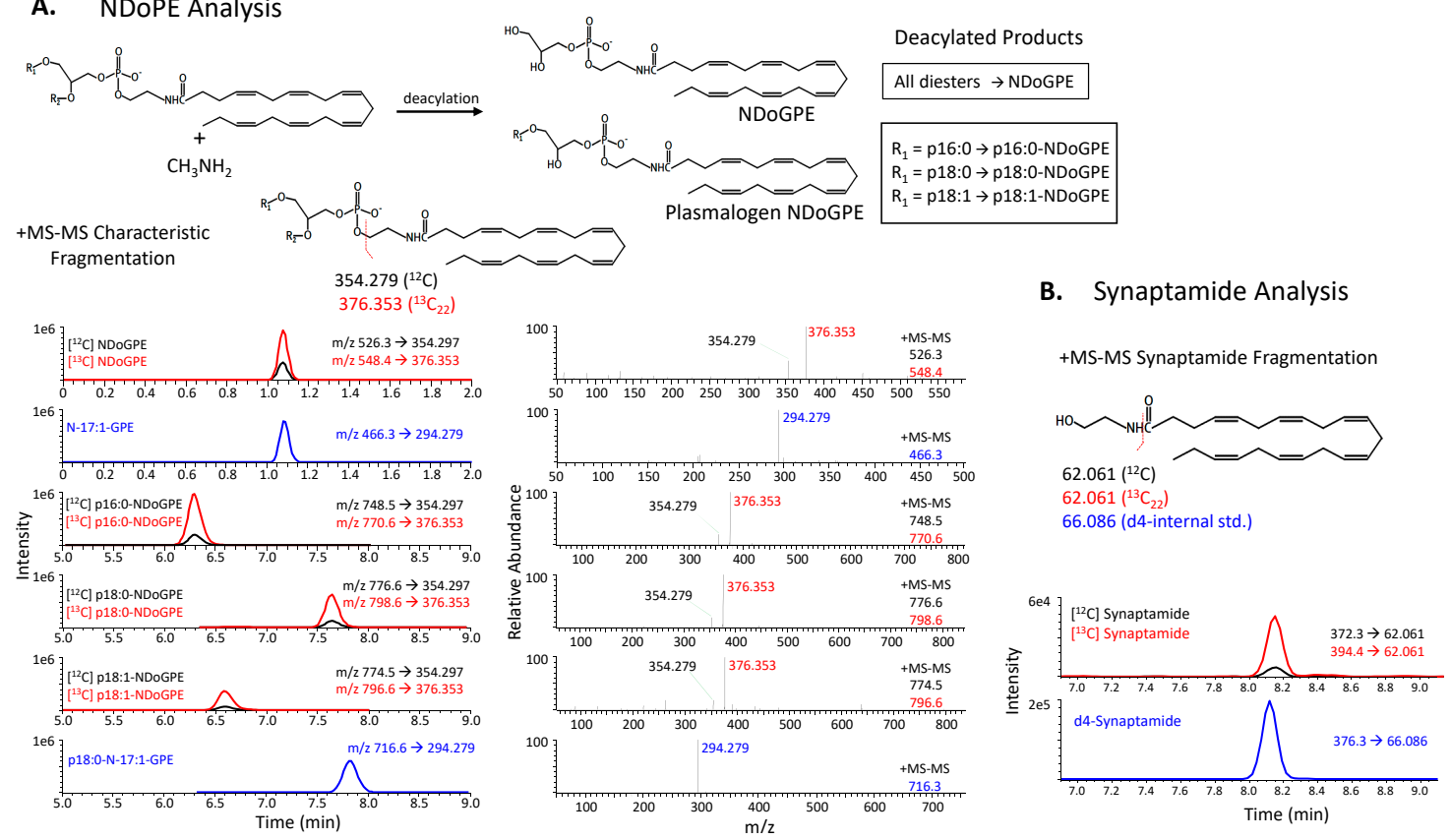

Figure 8. Quantitative analysis of NDoPE and synaptamide by LC-MS/MS. (A) Conversion of diverse NDoPE molecular species to four NDoPE-derived species including $\mathrm{N}$-docosahexaenoyl-glycerylphosphatidylethanolamine $\quad$ (NDoGPE), 1-p16:0-, 1-p18:0, and 1-p18:1-NDoGPE by methylamine-mediated deacylation, simplifying mass spectrometric analysis on the basis of the characteristic fragments at $m / z 354.279$ and $m / z 376.353$ formed in the positive ion MS/MS mode (top), and representative ion chromatograms of deacylated NDoPE derived from Neuro2A cells treated with $8 \mu \mathrm{M}\left[{ }^{13} \mathrm{C}\right] \mathrm{DHA}$ and $2 \mu \mathrm{M}$ fatty acid amide hydrolase (FAAH) inhibitor for $8 \mathrm{~h}$ (bottom). The black and red traces correspond to the NDoPE classes derived from endogenous sources and exogenously added $\left[{ }^{13} \mathrm{C}\right] \mathrm{DHA}$, respectively. Blue traces are MS/MS signals for N-17:1-GPE and 1-p18:0-N-17:1-GPE derived from internal standards (15:0,d7-18:1-N-17:1-PE and p18:0,20:4-N-17:1-PE, respectively). (B) The positive ion MS/MS fragmentation schematic (left) and representative LC-MS/MS ion chromatograms (right) of synaptamide obtained from Neuro2A cell culture media after incubation with $8 \mu \mathrm{M}\left[{ }^{13} \mathrm{C}\right] \mathrm{DHA}$ and $2 \mu \mathrm{M}$ FAAH inhibitor for $8 \mathrm{~h}$. Both the natural (black trace) and ${ }^{13} \mathrm{C}$-labeled synaptamide (red trace) produced a characteristic fragment at $\mathrm{m} / \mathrm{z} 62.061$ that was used for quantitation against the corresponding fragment from $\mathrm{d}_{4}$-synaptamide internal standard at $m / z 66.086$ (blue trace).

Deacylated NDoPE samples were injected onto a Gemini-NX C18 LC column $(150 \mathrm{~mm} \times 2.1 \mathrm{~mm}$, $5 \mu$, Phenomenex), which was coupled to Q-Exactive mass spectrometer to detect the four resulting classes of deacylated compounds, $N$-docosahexaenoyl-glycerylphosphatidylethanolamine (NDoGPE), 1-p16:0-N-DHA-GPE, 1-p18:0-NDoGPE, 1-p18:1-NDoGPE, and 1,2-lyso-N-DHA-GPE. LC separation was achieved utilizing a 2-solvent system at $0.4 \mathrm{~mL} / \mathrm{min}$ flow rate, as described previously [49]: $0.1 \%$ $\mathrm{NH}_{4} \mathrm{OH}$ (Fisher Scientific) in solvent A (88\%/12\% methanol/water) and B (88\%/12\% methanol/n-hexane (Fisher Scientific)). The gradient consisted of $100 \%$ A for $3 \mathrm{~min}$, followed by a linear change to $100 \%$ B over $18 \mathrm{~min}$. The column was held at 100\% B for an additional $6 \mathrm{~min}$. Between each sample, the column was reconditioned with $0.1 \mathrm{M}$ ammonium acetate (Sigma-Aldrich) for 3 min followed by $100 \%$ A for $3 \mathrm{~min}$. The mass spectrometer was run in positive MS/MS mode, and quantitation of each deacylated NDoPE class was achieved via the fragment ions [39] arising from transitions 526.3 to 354.279 (NDoGPE), 548.4 to 376.353 ([13C]NDoGPE), 748.5 to 354.279 (1-p16:0-NDoGPE), 770.6 to 376.353 (1-p16:0-[13C]NDoGPE), 776.6 to 354.279 (1-p18:0-NDoGPE), 798.6 to 376.353 (1-p18:0-[13C]NDoGPE), 774.5 to 354.279 (1-p18:1-NDoGPE), and 796.6 to 376.353 (1-p18:1-[13C]NDoGPE). Peak areas of these transition fragments were compared to those from the N-17:1-PE internal standards: 466.3 to 294.279 (N-17:1-GPE) and 716.6 to 294.279 (1-p18:0-N-17:1-GPE) for diacyl and plasmalogen species, respectively. 


\subsection{Synaptamide Analysis}

The procedure for synaptamide analysis is illustrated in Figure 8B. A mixture of deuterated internal standards including $\mathrm{d}_{4}$-synaptamide, $\mathrm{d}_{5}$-DHA, and $\mathrm{d}_{8}$-AA (deuterated free fatty acids, Cayman Chemical, Ann Arbor, MI, USA) was added to media samples, which were made 7:3 BHT-methanol/water and centrifuged for $20 \mathrm{~min}$ at $4{ }^{\circ} \mathrm{C}$. Supernatants were loaded onto Strata- $\mathrm{X}$ polymeric C18 reverse-phase SPE cartridges $(33 \mu, 30 \mathrm{mg} / \mathrm{mL}$, Phenomenex) that were wetted with BHT-methanol and equilibrated with water. After being washed with water, samples were eluted with $2.5 \mathrm{~mL}$ BHT-methanol into glass tubes, dried under $\mathrm{N}_{2}$, and suspended in $25 \mu \mathrm{L}$ BHT-methanol. An Eclipse C18 UHPLC column $(1.8 \mu, 2.1 \mathrm{~mm} \times 50 \mathrm{~mm}$, Agilent Technologies, Santa Clara, CA, USA) was coupled to a high-resolution Thermo Scientific Q-Exactive mass spectrometer for analysis. A 3-part tertiary gradient, with all solvents containing $0.01 \%$ acetic acid, consisting of water (A), methanol (B), and acetonitrile (Avantor, Radnor Township, PA, USA) (C) was used for LC. After pre-equilibration of column with $\mathrm{A} / \mathrm{B}(60 \% / 40 \%), 5 \mu \mathrm{L}$ extract was injected and the solvent composition was linearly changed to $\mathrm{A} / \mathrm{B} / \mathrm{C}(36.3 \% / 15 \% / 48.7 \%)$ in $5 \mathrm{~min}$, followed by a linear gradient to $\mathrm{A} / \mathrm{B} / \mathrm{C}(13.5 \% / 68.4 \% / 18.1 \%)$ over $22 \mathrm{~min}$. Positive ion MS/MS was utilized to detect natural, $\left[{ }^{13} \mathrm{C}\right]$-, and $\mathrm{d}_{4}$-synaptamide, using mass transitions of 372.3 to $62.060,394.4$ to 62.060 , and 376.3 to 66.085 , respectively. The fully labeled $\left[{ }^{13} \mathrm{C}\right]$ synaptamide signal (394.4 to 62.060 ) was corrected according to the unique isotope distribution for the synaptamide production from the ${ }^{13} \mathrm{C}$-labeled substrates. Quantitation of fatty acid and DHA-lysoPC was achieved by comparison of peak areas of $[\mathrm{M}+\text { Acetate }]^{-}$or $[\mathrm{M}+\mathrm{H}]^{+}$ions to that of the corresponding internal standard.

\subsection{Total Lipid Analysis}

The remaining $10 \%$ of Neuro2A cell Bligh-Dyer lipid extract (see deacylated NDoPE analysis) was transmethylated with boron trifluoride/methanol (Sigma-Aldrich) in the presence of a 23:0 fatty acid internal standard NuChek Prep), and the reaction product was extracted into hexane (Thermo Fisher Scientific). GC analysis was similar to that previously described [49]. The transmethylated samples were injected onto an Agilent 6890 gas chromatograph with a flame ionization detector via a $15 \mathrm{~m}$ DB-FFAP phase capillary column (Agilent Technologies). Fatty acid methyl esters were identified according to the elution time and quantified on the basis of the peak area in comparison to the 23:0 internal standard.

\subsection{NAPE-PLD Inhibition}

Effects of the NAPE-PLD inhibitors hexachlorophene and bithionol (Sigma-Aldrich) [29] on cell viability were tested in the presence of $2 \mu \mathrm{M}$ FAAH inhibitor URB597. Neuro2A cells were seeded at approximately $40 \%$ confluency into a 96-well culture plate in 5\% FBS/DMEM medium. Then, $24 \mathrm{~h}$ later, the media was aspirated and replaced with $0.25 \%$ FBS/DMEM containing $2 \mu M$ URB597 and 0,5 , or $10 \mu \mathrm{M}$ hexachlorophene or bithionol, and the incubation was continued for 1.5 or $2.5 \mathrm{~h}$ at 37 ${ }^{\circ} \mathrm{C}$. Cells were lysed and viability determined by an ATP-based luminescence assay (CellTiter-Glo Luminescent Cell Viability Assay Kit, Promega, Madison, WI).

The effect of these NAPE-PLD inhibitors on $\left[{ }^{13} \mathrm{C}\right]$ synaptamide production was also tested in the presence of $2 \mu \mathrm{M}$ URB597. Neuro2A cells were seeded into 6-well plates (5\% FBS/DMEM) and incubated overnight. After changing the medium to $0.25 \%$ FBS/DMEM containing $2 \mu \mathrm{M}$ URB597 and $10 \mu \mathrm{M}$ hexachlorophene or bithionol and incubating for $15 \mathrm{~min}$ at $37{ }^{\circ} \mathrm{C}$, we added $\left[{ }^{13} \mathrm{C}\right] \mathrm{DHA}$ to each well along with $40 \mu \mathrm{M}$ vitamin $\mathrm{E}$, and incubated it for $2 \mathrm{~h}$ at $37^{\circ} \mathrm{C}$. Media was collected and d4-synaptamide internal standard was added. Media samples were processed and analyzed as described above. For this assay, endogenous anandamide was also quantitated, utilizing $\mathrm{d}_{4}$-synaptamide as an internal standard. 


\subsection{Statistical Analysis}

The quantitative results are expressed as means \pm standard deviation for triplicate samples, except for viability test of Neuro2A cells incubated with NAPE-PLD inhibitors, where means were based on quadruplicate samples. Statistical analyses were conducted using Student's $t$-test (Excel software, Microsoft, Redmond, WA, USA). Statistical significance is reported at ${ }^{*} p<0.05,{ }^{* *} p<0.01$, and ${ }^{* * *} p<0.001$.

Author Contributions: Conceptualization, H.-Y.K. and A.A.S.; methodology, K.K., M.L., and H.-Y.K.; formal analysis, H.-Y.K., K.K., and A.A.S.; resources, H.-Y.K. and M.L.; writing-original draft preparation, A.A.S., K.K., M.L., and H.-Y.K.; project administration, H.-Y.K.; funding acquisition, H.-Y.K. All authors have read and agreed to the published version of the manuscript.

Funding: This work was supported by intramural research funding from the National Institute of Alcohol Abuse and Alcoholism, National Institutes of Health.

Conflicts of Interest: The authors declare no potential conflict of interest.

\section{Abbreviations}

$\begin{array}{ll}\text { BHT } & t \text {-Butyl hydroxytoluene } \\ \text { DCM } & \text { Dichloromethane } \\ \text { DHA } & \text { Docosahexaenoic acid } \\ \text { DHA-lysoPC } & \text { Docosahexaenoyl lysophosphatidylcholine } \\ \text { DMEM } & \text { Dulbecco's minimum essential medium } \\ \text { DMSO } & \text { Dimethyl sulfoxide } \\ \text { FAAH } & \text { Fatty acid amide hydrolase } \\ \text { FBS } & \text { Fetal bovine serum } \\ \text { GC } & \text { Gas-liquid chromatography } \\ \text { GPC } & \text { Glycerophosphorylcholine } \\ \text { GPE } & \text { Glycerophosphorylethanolamine } \\ \text { LC } & \text { Liquid chromatography } \\ \text { LC-MS } & \text { Liquid chromatography/mass spectrometry } \\ \text { lysoPC } & \text { Lysophosphatidylcholine } \\ \text { NAE } & \text { N-Acylethanolamine } \\ \text { NAPE } & N \text {-Acylphosphatidylethanolamine } \\ \text { NAPE-PLD } & N \text {-Acylphosphatidylethanolamine-phospholipase D } \\ \text { NDoGPE } & N \text {-Docosahexaenoylglycerolphosphorylethanolamine } \\ \text { NDoPE } & N \text {-Docosahexaenoylphosphatidylethanolamine } \\ \text { PBS } & \text { Phosphate-buffered saline } \\ \text { PE } & \text { Phosphatidylethanolamine } \\ \text { pNDoPE } & \text { Plasmalogen-NDoPE } \\ \text { SPE } & \text { Solid-phase extraction } \\ \text { Synaptamide } & N \text {-Docosahexanoylethanolamine } \\ & \end{array}$

\section{References}

1. Kim, H.-Y.; Spector, A.A. N-docosahexanoylethanolamine: A neurotrophic and neuroprotective metabolite of docosahexaenoic acid. Mol. Asp. Med. 2018, 64, 34-44. [CrossRef]

2. Kim, H.-Y.; Moon, H.S.; Cao, D.; Lee, J.; Kevala, K.; Jun, S.; Lovinger, D.; Akbar, M.; Huang, B.X. $\mathrm{N}$-docosahexaenoylethanolamide promotes development of hippocampal neurons. Biochem. J. 2011, 435, 327-336. [CrossRef] [PubMed]

3. Rashid, M.A.; Katakura, M.; Kharebava, G.; Kevala, K.; Kim, H.-Y. N-docosahexaenoylethanolamine is a potent neurogenic factor for neural stem cell differentiation. J. Neurochem. 2013, 125, 869-884. [CrossRef] [PubMed]

4. Park, T.; Chen, H.; Kevala, K.; Lee, J.; Kim, H.-Y. N-docosahexaenoylethanolamine ameliorates LPS-induced neuroinflammation via cAMP/PKA-dependent signaling. J. Neuroinflamm. 2016, 13, 284. [CrossRef] [PubMed] 
5. Lee, J.W.; Huang, B.X.; Kwon, H.S.; Rashid, M.A.; Kharebava, G.; Desai, A.; Patnaik, S.; Marugan, J.; Kim, H.-Y. Orphan GPR110 (ADGRF1) targeted by N-docosahexaenoylethanolamine in development of neurons and cognitive function. Nat. Commun. 2016, 7, 13123. [CrossRef] [PubMed]

6. Devane, W.A.; Hanuš, L.; Breuer, A.; Pertwee, P.G.; Stevenson, L.A.; Griffin, G.; Gibson, D.; Mandelbaum, A.; Ettinger, A.; Mechoulam, R. Isolation and structure of a brain constituent that binds to the cannabinoid receptor. Science 1992, 258, 1946-1949. [CrossRef]

7. Felder, C.C.; Briley, E.M.; Axelrod, J.; Simpson, J.T.; Mackie, K.; Devane, W.A. Arachidonoyl ethanolamide, an endogenous cannabinoid eicosanoid, binds to the cloned human cannabinoid receptor and stimulates receptor-mediated signal transduction. Proc. Natl. Acad. Sci. USA 1993, 90, 7656-7660. [CrossRef]

8. Deutsch, D.G.; Chin, S.A. Enzymatic synthesis and degradation of anandamide, a cannabinoid receptor agonist. Biochem. Pharmacol. 1993, 46, 791-796. [CrossRef]

9. Devane, W.A.; Axelrod, J. Enzymatic synthesis of anandamide, an endogenous ligand for the cannabinoid receptor, by brain membranes. Proc. Natl. Acad. Sci. USA 1994, 91, 6698-6701. [CrossRef]

10. Kruszka, K.A.; Gross, R.W. The ATP- and CoA-independent synthesis of arachidonoylethanolamide. J. Biol. Chem. 1994, 269, 14345-14348.

11. Schmid, H.H.O.; Schmid, P.C.; Natarajan, V. N-acylation-phosphodiesterase pathway and cell signaling. Chem. Phys. Lipids 1996, 80, 133-142. [CrossRef]

12. Schmid, H.H.O.; Schmid, P.C.; Natarjan, V. N-acylated glycerophospholipids and their derivatives. Prog. Lipid Res. 1990, 29, 1-43. [CrossRef]

13. DiMarzo, V.; Fontana, A.; Cadas, H.; Schnelli, S.; Cimino, G.; Schwartz, J.C.; Piomelli, D. Formation and inactivation of endogenous cannabinoid anandamide in central neurons. Nature 1994, 372, 686-691. [CrossRef] [PubMed]

14. Cadas, H.; Gaillet, S.; Beltramo, M.; Venance, L.; Piomelli, D. Biosynthesis of an endogenous cannabinoid precursor in neurons and its control by calcium and cAMP. J. Neurosci. 1996, 16, 3934-3942. [CrossRef]

15. Cadas, H.; Tomaso, E.D.; Piomelli, D. Occurrence and biosynthesis of endogenous cannabinoid precursor, $\mathrm{N}$-arachidonoyl phosphatidylethanolamine, in rat brain. J. Neurosci. 1997, 17, 1226-1242. [CrossRef]

16. Suguira, T.; Kondo, S.; Sukagawa, A.; Tonegawa, T.; Nakane, S.; Yamashita, A.; Ishima, Y.; Waku, K. Transacylase-mediated and phosphodiesterase-mediated synthesis of $N$-arachidonoylethanolamine, an endogenous cannabinoid-receptor ligand, in rat brain microsomes. Comparison with synthesis from free arachidonic acid and ethanolamine. Eur. J. Biochem. 1996, 240, 53-62. [CrossRef]

17. Hillard, C.J.; Campbell, W.B. Biochemistry and pharmacology of arachidonoylethanolamide, a putative endogenous endocannabinoid. J. Lipid Res. 1997, 38, 2383-2398.

18. Natarajan, V.; Reddy, P.V.; Schmid, P.C.; Schmid, H.H.O. On the biosynthesis and metabolism of $\mathrm{N}$-acylethanolamine phospholipids in infarcted dog heart. Biochim. Biophys. Acta 1981, 664, 445-448. [CrossRef]

19. Reddy, P.V.; Natarajan, V.; Schmid, P.C.; Schmid, H.H.O. N-acylation of dog heart ethanolamine phospholipids by transacylase activity. Biochim. Biophys. Acta 1983, 750, 472-480. [CrossRef]

20. Natarajan, V.; Schmid, P.C.; Schmid, H.H.O. N-acylethanolamine phospholipid metabolism in normal and ischemic rat brain. Biochim. Biophys. Acta 1986, 878, 32-41. [CrossRef]

21. Uyama, T.; Ikematsu, N.; Inoue, M.; Shinohara, N.; Jin, X.H.; Tsuboi, K.; Tonai, T.; Tokumura, A.; Ueda, N. Generation of $\mathrm{N}$-acylphosphatidylethanolamine by members of the phospholipase A/acyltransferase (PLA/AT) family. J. Biol. Chem. 2012, 287, 31905-31919. [CrossRef] [PubMed]

22. Bisogno, T.; Delton-Vanderbroucke, I.; Milone, A.; Lagarde, M.; DiMarzo, V. Biosynthesis and inactivation of $\mathrm{N}$-arachidonoyl ethanolamine (anandamide) and $\mathrm{N}$-docosahexaenoyl ethanolamine in bovine retina. Arch. Biochem. Biophys. 1999, 370, 300-307. [CrossRef] [PubMed]

23. Urquhart, P.; Wang, J.; Woodward, D.F.; Nicolaou, A. Identification of prostamides, fatty acyl ethanolamides and their biosynthetic precursors in rabbit cornea. J. Lipid Res. 2015, 56, 1419-1433. [CrossRef] [PubMed]

24. Thiès, F.; Pillon, C.; Molière, P.; Lagarde, M.; Lecerf, J. Preferential incorporation of sn-2 lysoPC DHA over unesterified DHA in the young rat brain. Am. J. Physiol. Regul. Integr. Comp. Physiol. 1994, 36, R1273-R1279. [CrossRef] [PubMed]

25. Rapoport, S.I.; Chang, M.C.J.; Spector, A.A. Delivery and turnover of plasma-derived and essential PUFAs in mammalian brain. J. Lipid Res. 2001, 42, 678-685. [PubMed] 
26. Nguyen, L.N.; Ma, D.; Shui, G.; Wong, P.; Cazenave-Gassiot, A.; Nguyen, L.N.; Zhang, X.; Wenk, M.; Goh, E.L.K.; Silver, D.L. Mfsd2a is a transporter for the essential omega-3 fatty acid docosahexaenoic acid. Nature 2014, 509, 503-506. [CrossRef]

27. Bazinet, R.P.; Bernoud-Hubac, N.; Lagarde, M. How the plasma lysophospholipid and unesterified fatty acid pools supply the brain with docosahexaenoic acid. Prostaglandins Leukot. Essent. Fat. Acids 2019, 142, 1-3. [CrossRef]

28. Kharebava, G.; Rashid, M.A.; Li, J.W.; Sarkar, S.; Kevala, K.; Kim, H.-Y. N-docosahexaenoylethanolamine regulates Hedgehog signaling and promotes growth of cortical axons. Biol. Open 2015, 4, 1660-1670. [CrossRef]

29. Aggarwal, G.; Zarrow, J.E.; Mashhadi, Z.; Flynn, C.R.; Vinson, P.; Weaver, C.D.; Davies, S.S. Symmetrically substituted dichlorophenes inhibit $N$-acyl-phosphatidylethanolamine phospholipase D. J. Biol. Chem. 2020, 295, 7289-7300. [CrossRef]

30. Croset, M.; Brossard, N.; Polette, N.; Lagard, M. Characterization of plasma unsaturated lysophosphatidylcholines in human and rat. Biochem. J. 2000, 345, 61-67. [CrossRef]

31. Bowden, J.A.; Heckert, A.; Ulmer, C.Z.; Jones, C.M.; Koelmel, J.P.; Abdullah, L.; Ahonen, L.; Alnouti, Y.; Armando, A.M.; Asara, J.M.; et al. Harmonizing lipidomics: NIST interlaboratory comparison exercise for lipidomics using SRM 1950-Metabolites in Frozen Human Plasma. J. Lipid Res. 2017, 58, 2276-2288. [CrossRef]

32. Hamilton, J.A.; Johnson, R.A.; Corkey, B.; Kamp, F. Fatty acid transport. The diffusion mechanism in model and biological membranes. J. Mol. Neurosci. 2001, 16, 99-108. [CrossRef]

33. Jay, A.G.; Simard, J.N.; Huang, N.; Hamilton, J.A. SSO and other putative inhibitors of FA transport across membranes by CD36 disrupt intracellular metabolism but do not affect FA translocation. J. Lipid Res. 2020, 61, 790-807. [CrossRef]

34. Pownall, H.J. Commentary on SSO and other putative inhibitors of FA transport across membranes by CD36 disrupt intracellular metabolism but do not affect FA translocation. J. Lipid Res. 2020, 61, 595-597. [CrossRef]

35. Glatz, J.F.C.; Luiken, J.J.F.P.; Bonen, A. Involvement of membrane-associated proteins in the acute regulation of cellular fatty acid uptake. J. Mol. Neurosci. 2001, 16, 123-132. [CrossRef]

36. Veerkamp, J.H.; Zimmerman, A.W. Fatty acid binding proteins of nervous tissue. J. Mol. Neurosci. 2001, 16, 133-142. [CrossRef]

37. Glatz, J.F.C.; Luiken, J.J.F.P. Time for a détente in the war on the mechanism of cellular fatty acid uptake. J. Lipid Res. 2020, 61, 1300-1303. [CrossRef]

38. Epps, D.E.; Natarajan, V.; Schmid, P.C.; Schmid, H.H.O. Accumulation of N-acylethanolamine glycerophospholipids in infarcted myocardium. Biochim. Biophys. Acta 1980, 618, 420-430. [CrossRef]

39. Natarajan, V.; Schmid, P.C.; Reddy, P.V.; Zuzarte-Augustin, M.L.; Schmid, H.H.O. Biosynthesis of $\mathrm{N}$-acylethanolamine phospholipids by dog brain preparations. J. Neurochem. 1983, 41, 1303-1312. [CrossRef]

40. Natarajan, V.; Schmid, P.C.; Reddy, P.V.; Zuzarte-Augustin, M.L.; Schmid, H.H.O. Occurrence of $\mathrm{N}$-acylethanolamine phospholipids in fish brain and spinal cord. Biochim. Biophys. Acta 1985, 835, 426-433. [CrossRef]

41. Leishman, E.; Mackie, K.; Luquet, S.; Bradshaw, H.B. Lipidomic profile of a NAPE-PLD KO mouse provides evidence for a broader role of this enzyme in lipid metabolism in the brain. Biochim. Biophys. Acta 2016, 1861, 491-500. [CrossRef]

42. Simon, G.M.; Cravatt, B.F. Endocannabinoid synthesis proceeding through glycerophospho- $N$-acylethanolamine and a role for alpha/beta-hydrolase 4 in this pathway. J. Biol. Chem. 2006, 281, 26465-26472. [CrossRef]

43. Simon, G.M.; Cravatt, B.F. Characterization of mice lacking candidate $N$-acyl ethanolamine biosynthetic enzymes provides evidence for multiple pathways that contribute to endocannabinoid pathways in vivo. Mol. BioSyst. 2010, 6, 1411-1418. [CrossRef]

44. Liu, J.; Wang, L.; Harvey-White, J.; Osei-Hyiaman, D.; Razdan, R.; Gong, Q.; Chan, A.C.; Zhou, Z.; Huang, B.X.; Kim, H.-Y.; et al. A biosynthetic pathway for anandamide. Proc. Natl. Acad. Sci. USA 2006, 103, 13345-13350. [CrossRef]

45. Hachem, M.; Géloën, A.; Lo Van, A.; Fourmaux, B.; Fenart, L.; Gosselet, F.; Da Silva, P.; Breton, G.; Lagarde, M.; Picq, M.; et al. Efficient docosahexaenoic acid uptake by the brain from a structured phospholipid. Mol. Neurosci. 2016, 53, 3205-3215. [CrossRef] 
46. Triebl, A.; Weissengruber, S.; Trötzmüller, M.; Lankmayr, E.; Köfeler, H. Quantitative analysis of $\mathrm{N}$-acylphosphatidylethanolamine molecular species in rat brain using solid-phase extraction combined with reversed-phase chromatography and tandem mass spectrometry. J. Sep. Sci. 2016, 39, 2474-2480. [CrossRef]

47. Guo, L.; Amamath, V.; Davies, S.S. A liquid chromatography-tandem mass spectrometry method for measurement of $N$-modified phosphatidylethanolamines. Anal. Biochem. 2010, 405, 236-245. [CrossRef]

48. Bligh, E.G.; Dyer, W.J. A rapid method for total lipid extraction and purification. Can. J. Biochem. Physiol. 1959, 37, 911-917. [CrossRef]

49. Wen, Z.; Kim, H.-Y. Alterations in hippocampal phospholipid profile by prenatal exposure to ethanol. J. Neurochem. 2004, 89, 1368-1377. [CrossRef]

Publisher's Note: MDPI stays neutral with regard to jurisdictional claims in published maps and institutional affiliations.

(C) 2020 by the authors. Licensee MDPI, Basel, Switzerland. This article is an open access article distributed under the terms and conditions of the Creative Commons Attribution (CC BY) license (http://creativecommons.org/licenses/by/4.0/). 